\title{
Proceso a la impunidad de crímenes de lesa humanidad en América Latina (1989-1991)
}

\author{
Rodolfo Mattarollo*
}

Resumen

\begin{abstract}
El ensayo se plantea si el derecho internacional consuetudinario impone a los estados la obligación de castigar siempre ciertos crimenes, concretamente las violaciones más graves de los derechos humanos. La respuesta es afirmativa, a partir del desarrollo progresivo del derecho internacional contemporáneo. Para probar esta afirmación, el autor explora la legislación vigente y concluye analizando brevemente la situación en América Latina. El tema es transcendental a la hora de examinar la renuncia del Estado a ejercer plenamente su jurisdicción penal, al conceder indultos o amnistías a las violaciones más graves de los derechos humanos.
\end{abstract}

\section{Planteamiento del problema}

De acuerdo al derecho intemacional, los estados tienen la obligación de investigar y castigar, a través de los órganos jurisdiccionales y de acuerdo a las reglas del debido proceso legal, las violaciones graves y sistemáticas de los derechos humanos fundamentales. Sin embargo, frente al orden jurídico internacional, conviene examinar la renuncia del Estado a ejercer plenamente su jurisdicción penal, por lo general a través de los indultos o de las amnistías abiertas o encubiertas, frente a las violaciones más graves de los derechos humanos.

De todas maneras, este tema está en plena elaboración teórica y normativa, y requiere aún de mayores esfuerzos para "hacer avanzar el derecho", aparte de que se encuentra en el centro del

* Profesor titular de la facultad de ciencias sociales de la Universidad Nacional de Lomas de Zamora (Argentina). Profesor invitado en la Universidad René Descartes (París V). 


\section{Ciertas normas que reconocen derechos humanos fundamentales constituyen reglas imperativas del derecho internacional general... cuya derogación no está permitida.}

debate político en la región ${ }^{1}$.

\section{Las particularidades de la legalidad interna- cional}

El principio de legalidad en materia intemacional exige un texto, pero sólo para la norma de comportamiento, no para la norma de represión. Para la norma de comportamiento, ese texto es necesario para marcar que un comportamiento es criminal y no sólo ilícito, distinción que la sola costumbre no hace nacer siempre en forma nítida ${ }^{2}$.

Ese texto no es necesariamente el de un tratado, puede ser una resolución de un organismo internacional o una sentencia de un tribunal internacional. Sin embargo, la costumbre puede dar lugar a la norma de comportamicnto: un comportamiento se volverá ilícito en ese caso, porque la mayor parte de los estados se abstienen con el sentimiento de ejecutar de esa manera una obligación jurídi$\mathrm{ca}^{3}$.

Lo que se vicne afirmando se compadece enteramente con la previsión del artículo 15 del Pacto Internacional de Derechos Civiles y Políticos que, al establecer el principio de legalidad, afirma en su segundo párrafo: "Nada de lo dispuesto en cste artículo se opondrá al juicio ni a la condena de una persona por actos u omisiones que, en cl momento de cometerse, fucran deliclivos, scgún los principios generales del derecho reconocidos por la comunidad internacional".

En ese supuesto, vale decir el juicio y la condena pueden corresponder aún en ausencia de norma de represión escrita y ante la sola existencia de una obligación jurídica de comportamiento, cuya violación se considere criminal y que puede surgir a su vez de la costumbre. Tal es la particularidad de la legalidad internacional que se reduce a la sola norma de comportamiento, la que además puede ser consuctudinaria, aunque la doctrina reclama su formulación escrita.

Una norma similar a la del pacto se encuentra en la Convención europea de derechos humanos (artículo 7 (2) cuyo sentido fue aclarado por la aplicación que recibió, 30 de mayo de 1961, Reg. 931/ 60 ), la que justificó la condena, en virtud de una ley noruega retroactiva, que incriminaba la colaboración con la administración alemana de ocupación.

3. Derechos fundamentales y normas imperativas

Ciertas normas que reconocen derechos humanos fundamentales constituyen reglas imperativas del derecho intcrnacional general (jus cogens), cuya derogación no está permitida (Corte Internacional de Justicia, asunto de la Barcelona Traclion, fallo del 5 de (ebrero de 1970).

Por lo menos determinadas normas de la Declaración Universal tienen indudablemente el carácler de normas impcrativas (jus cogens). Tal es el caso de las que aparecen quebrantadas en las tres violaciones más graves de los derechos humanos individuales que se registran en la actualidad: las ejecuciones sumarias o extralegales, las desapariciones forzadas o involuntarias de personas, $y$ la práctica de la tortura.

En efecto, se ha alirmado que existe un "núcleo esencial" del que derivan muchos otros derechos humanos, definido como el "derecho a la vida, la liberlad y la seguridad de la persona", reconocido en el artículo 3 de la Declaración Univer$\mathrm{sal}^{4}$. Puede afirmarse con fundamento que ese "núcleo esencial" tiene hoy el carácter de norma imperativa del derecho internacional general (jus cogens).

Igualmente, la tortura constituye una violación del derecho internacional consuetudinario e incluso de las normas imperativas del derecho internacional general (jus cogens): se ha afirmado que "como la piratería, la esclavitud y el genocidio con anterioridad, la prohibición de la tortura es hoy una norma imperativa del derecho internacional" 
(jus cogens) ${ }^{5}$.

Un criterio que puede contribuir a la identificación de las normas de jus cogens es el de su intangibilidad (prohibición expresa de suspensión), si bien ésta es una consecuencia del carácter imperativo de dichas normas. Es sabido que, no obstante las diferencias que existen a este respecto entre los diversos instrumentos internacionales de derechos humanos, hay coincidencias en lo que se refiere al núcleo esencial de la dignidad humana: el derecho a la vida y la inmunidad contra la tortura (ver, por ejemplo, el Pacto Intemacional de Derechos Civiles y Políticos, art. 4, 2 y la Convención Americana sobre Derechos Humanos, art. 27, 2).

\section{Derechos humanos y crímenes internaciona- les}

Puede afirmarse con certeza, aún cuando la cucstión no es todavía pacífica en doctrina, que la vulneración de las normas de jus cogens y en particular de las que reafirman los derechos humanos fundamentales, constituyen crímenes internacionales ${ }^{6}$.

La asimilación de las más graves violaciones de los derechos humanos como la tortura, las desapariciones forzadas y las ejecuciones sumarias, a los crímenes de lesa humanidad, se inscribe en la profunda evolución del derecho penal internacional, posterior a la segunda guerra mundial?

En el Proyecto de Código de Delitos contra la Paz y la Seguridad de la Humanidad —elaborado por la Comisión de Derecho Internacional de las Naciones Unidas-, el artículo 2 enumera un conjunto de actos que constituyen tales delitos y entre ellos, su inciso 11) incluye los siguientes: "los actos inhumanos, tales como el asesinato, el exterminio, la esclavitud, la deportación o las persecuciones contra cualquier población civil por motivos sociales, políticos, raciales, religiosos o culturales, perpetrados por las autoridades de un Estado o por particulares que actúen por instigación de dichas autoridades o con su tolerancia".

Precisamente, entre las fuentes del derecho internacional -que comprenden la jurisprudencia y la doctrina como medio auxiliar para determinar las reglas del derecho- los mencionados trabajos de la Comisión de Derecho Internacional y los pronunciamientos de la Corte Internacional de Justicia -en especial en el asunto de la Barcelona Traction y su opinión consultiva sobre las reservas a la Convención contra el genocidio- apuntalan la asimilación actual de las graves violaciones de los derechos humanos a los crímenes internacionales $^{8}$.

Por su parte, refiriéndose a las desapariciones forzadas de personas, la Corte Interamericana de Derechos Humanos ha recordado en dos oportunidades que "Si bien no existe ningún texto convencional en vigencia, aplicable a los estados partes en la Convención (Americana de Derechos Humanos), que emplee esta denominación, la doctrina y la práctica internacionales han calificado muchas veces las desapariciones como un delito contra la humanidad (Anuario Interamericano de Derechos Humanos, 1985, págs. 369, 687 y 1103)".

A continuación, la Corte hizo referencia en ambas oportunidades a la resolución de la asamblea de la OEA que definió las desapariciones forzadas como crímenes de "lesa humanidad" (ver nota 12 in fine)'.

De la misma forma existe hoy un amplio consenso en considerar que la tortura constituye un 
crimen de derecho internacional, como lo establecía el artículo 1 del proyecto de convención sobre la prevención y la supresión de la tortura de la Asociación Internacional de Derecho Penal ${ }^{10}$.

\section{El ejercicio de la jurisdicción como obliga- ción del Estado}

Como consecuencia de lo expuesto, puede volver a plantearse ahora el interrogante de si el derecho internacional consuetudinario impone a los estados la obligación de castigar siempre ciertos crímenes. El desarrollo progresivo del derecho internacional contemporáneo parece inspirar una respuesta positiva, no obstante las reservas que se han expresado al respecto (ver nota 2).

Puede plantearse ahora la cuestión frente a la labor de codificación y luego al desarrollo progresivo del derecho internacional tal como resulta de las resoluciones de la Asamblea General de las Naciones Unidas. A continuación se mencionan las normas convencionales y las contenidas en algunas resoluciones especialmente importantes de la Asamblea General que establecen la necesaria represión penal y el obligatorio ejercicio de la jurisdicción judicial frente a las violaciones más graves de los derechos humanos.

Las principales normas convencionales ap!icables son los artículos IV y $\mathrm{V}$ de la Convención para la Prevención y la Sanción del Delito de Genocidio, el artículo 4 de la Convención contra la Tortura y Otros Tratos o Penas Crueles, Inhumanos o Degradantes de las Naciones Unidas y el artículo 6 de la Convención Interamericana para Prevenir y Sancionar la Tortura, el artículo IV de la Convención Internacional sobre la Represión y el Castigo del Crimen de Apartheid y el artículo IV de la Convención sobre la Imprescriptibilidad de los Crímenes de Guerra y los Crímenes de Lesa Humanidad.

A su vez, deben tenerse en cuenta, en su propio ámbito de vigencia, las "infracciones graves" a los Convenios de Ginebra de 1949 y a sus Protocolos Adicionales I y II, en la medida en que resulten aplicables y de acuerdo con una interpretación amplia de la compleja cuestión de la represión penal en los conflictos armados internos. La
Convención sobre el Genocidio dispone que las personas que hayan cometido genocidio y otros actos que enumera en su artículo III "serán castigadas, ya se trate de gobernantes, funcionarios o particulares".

La Convención contra la Tortura de las Naciones Unidas dispone:

Artículo 4

1. Todo Estado Parte velará porque todos los actos de tortura constituyan delitos conforme a su legislación penal. Lo mismo se aplicará a toda tentativa de cometer tortura y a todo acto de cualquier persona que constituya complicidad o participación en la tortura.

2. Todo Estado Parte castigará esos delitos con penas adecuadas en las que se tenga en cuenta su gravedad.

La conclusión que se impone es que, en todos los casos debe aplicarse el castigo a quienes sean encontrados responsables de estos crímenes. La diferenciación que un prestigioso autor ha creído encontrar entre ambos textos - y que permitiría, en el caso de la tortura, el indulto o la amnistía posteriores a la sentencia- no parece justificada ${ }^{11}$.

A su vez el Artículo IV de la Convención sobre Imprescriptibilidad de los Crímenes de Guerra y Crímenes de Lesa Humanidad establece:

Artículo IV

Los Estados Partes en la presente Convención se comprometen a adoptar, con arreglo a sus respectivos procedimientos constitucionales, las medidas legislativas o de otra índole que fueran necesarias para que la prescripción de la acción penal o de la pena, establecida por ley o de otro modo, no se aplique a los crimenes mencionados en los artículos I y II de la presente Convención y, en caso de que exista, sea abolida.

Como se ve la Convención no se limita a prohibir para el futuro los efectos extintivos de la prescripción e incluye una norma que declara nula e inexistente la prescripción que pudiera haberse ya operado' ${ }^{12}$.

En lo que se refiere al desarrollo progresivo 
del derecho internacional, a través de las resoluciones de la Asamblea General de las Naciones Unidas, es preciso tener en cuenta la obligación de someter en todos los casos a la jurisdicción judicial a los sospechosos de haber participado cn ejecuciones sumarias. Esta obligación está establecida en los "Principios relativos a una eficaz prevención e investigación de las ejecuciones extralegales, arbitrarias o sumarias", confirmados mediante la Resolución 44/162 del 15 de diciembre de 1989 de la Asamblea General.

Según esa reciente resolución, "En ninguna circunstancia, ni siquiera en estado de guerra, de sitio o en otra emergencia pública, se otorgará inmunidad general previa de procesamiento a las personas supuestamente implicadas en ejecuciones extralegales, arbitrarias o sumarias (19 in fine). En consecuencia, frente al derecho intemacional, las amnistías previas al juicio y condena de los culpables, el indulto de los procesados y toda otra medida similar tendiente a evitar el procesamiento de los eventuales responsables de las ejecuciones sumarias son ilegales.

Por su parte los "Principios de cooperación internacional en la identificación, detención, extradición y castigo de los culpables de crímenes de guerra, o de crímenes de lesa humanidad" (resolución 3074 (XXVIII), de la Asamblea General, del 3 de diciembre de 1973) establece una norma aún más severa, ya que debe entenderse que en su ámbito de aplicación no existe inmunidad previa ni posterior de procesamiento:

1. Los crímenes de guerra y los crímenes de lesa humanidad, dondequiera y cualquiera que sea la fecha en que se hayan cometido, serán objeto de una investigación, y las personas contra las que existen pruebas de culpabilidad en la comisión de tales crímenes serán buscadas, detenidas, enjuiciadas y, en caso de ser declaradas culpables, castigadas.

\section{Las infracciones graves al derecho humani- tario}

En varios países latinoamericanos se plantean situaciones de conflicto armado interno en las que es aplicable el artículo 3 común de los cuatro con- venios de Ginebra del 12 de agosto de 1949, e inclusive, como ha ocurrido en El Salvador, el Protocolo Adicional II de 1977.

Los convenios de Ginebra y sus protocolos adicionales forman parte de las leyes y costumbres de la guerra, cuyas infracciones graves constituyen, según los casos, crímenes de guerra o crímenes de lesa humanidad, consistentes estos últimos genéricamente en un conjunto de actos crueles e inhumanos contra la población civil. Si bien se ha sostenido que la única norma de los convenios de Ginebra de 1949 aplicable en los conflictos armados internos es su artículo 3 común, una interpretación amplia de la cuestión sostiene que las violaciones de dicho artículo pueden constituir infracciones graves a los convenios, por lo que también serían aplicables sus normas penales y no sólo su artículo 3. La interpretación amplia se basa en el desarrollo progresivo del derecho internacional y en las características de la legalidad internacional, expuestas más arriba (ver punto 2 de este trabajo).

Ahora bien, como lo señala el autorizado comentario de los convenios de Ginebra de 1949, publicado por el Comité Internacional de la Cruz Roja, el sistema penal adoptado por dichos instrumentos internacionales está basado en tres obligaciones fundamentales:

a) La obligación de adoptar todas las medidas legislativas necesarias para fijar las adecuadas sanciones penales que hayan de aplicarse a las personas que cometan o den orden de cometer cualquiera de las infracciones graves.

b) La obligación de buscar a las personas acusadas de haber cometido o mandado cometer cualquiera de las infracciones graves.

c) La obligación de procesarlas ante sus propios tribunales, o de entregarlas para su juzgamiento a otro Estado respetando determinados requisitos ${ }^{13}$.

Se puede concluir que las normas convencionales antes citadas establecen una clara obligación de procesar judicialmente y castigar a los autores de las conductas incriminadas en todos los casos, como lo indica además la enfática inclusión de las "infracciones graves" a los convenios de Ginebra, 
en la "Convención sobre la imprescriptibilidad de los crímenes de guerra y de los crímenes de lesa humanidad" (artículo 1, a).

\section{Amnistía y derechos humanos según el re- lator especial de la ONU}

Un aspecto central del Informe Joinet es.la determinación de la improcedencia de la "amnistía recíproca" frente al derecho internacional, en la medida en que ésta muchas veces "tiende esencialmente a organizar la impunidad de los agentes estatales o paraestatales, autores de graves atentados a la dignidad humana"14.

En efecto la "amnistía recíproca" busca con frecuencia lograr el olvido de la violación de los derechos humanos cometida desde el Estado a cambio del perdón de los delitos atribuidos a la insurgencia o a la posición política. Sin embargo, lo que generalmente ha podido comprobarse es que la práclica sistemática de las violaciones más graves de los derechos humanos -las torturas, las ejecuciones sumarias y las desapariciones forzadas- se encuentran casi siempre en el mismo campo: el del Estado terrorista.

Por otra parte, todo el sistema internacional de protección de los derechos humanos está basado hasta ahora en una concepción según la cual es determinante la existencia de un elemento estatal, por acción o por omisión, en las conductas consideradas relevantes para el derecho internacional.

Algunas tendencias recientes, favorables a una ampliación del concepto de agentes violadores de los derechos humanos, deberían analizarse con detenimiento en sus múltiples implicaciones, aunque no es una discusión que corresponda realizar en esta oportunidad ${ }^{15}$. Por eso, el Relator especial señala la importancia de las sugerencias realizadas tanto por la Asamblea General como por la subcomisión para examinar las condiciones en las cuales la tortura, las desapariciones forzadas y las ejecuciones sumarias podrían, en ciertos casos y bajo ciertas condiciones, asimilarse a un crimen internacional o a un crimen de lesa humanidad. En esos casos — concluye Joinet-, se excluiría la amnistía.

Por eso, para el Relator aparece como una cuestión clave establecer cuándo las violaciones graves y sistemáticas de los derechos humanos pueden asimilarse a los crímenes de lesa humanidad. Tratará de hacerlo siguiendo las orientaciones extraídas de las jurisprudencias de Nuremberg y de Tokyo y, más recientemente, de la Comisión y de la Corte Europea de Derechos Humanos.

El Relator propone como concepto decisivo el de la sistematicidad de dichas violaciones. Al respecto, recuerda que la Corte Europea reconoce la existencia de una práctica administrativa (de la tortura) cuando se reúnan los dos elementos siguientes: (a) acumulación de infracciones de naturaleza idéntica o análoga, suficientemente numerosas o vinculadas entre sí como para no tratarse de incidentes aislados o de excepciones y susceptibles de formar un conjunto o sistema, y (b) tolerancia de parte de las autoridades superiores del Estado. Según el Relator:

Cuando estas condiciones están reunidas - tratándose de la tortura, las desapariciones involuntarias o forzadas o las ejecuciones extrajudiciales- el atentado a la "condición humana" es tal que el derecho al olvido amenaza transformarse en derecho a la impunidad ${ }^{16}$.

\section{La impunidad en América Latina}

En Argentina, cuando la última dictadura militar procuró su absoluta impunidad, mediante la sanción de la llamada ley 22.924 , el viernes 23 de septiembre de 1983, el país había conocido veintiséis amnistías políticas anteriores desde la revolución de mayo de 1810. Por lo general, se trató de casos en que el Estado perdonaba delitos políticos y comunes conexos, consistentes fundamentalmente en la rebelión contra las autoridades constituidas. Sin duda es completamente distinto el caso en que las mismas autoridades de un gobierno de facto promulgan normas para asegurar la impunidad de los crimenes que pueden serles reprochados.

\section{En todos los casos debe aplicarse el castigo a quienes sean encontrados responsables de estos crímenes.}


El sentido de la amnistía fue claro desde los orígenes del período constitucional argentino. La primera ley de amnistía sancionada por el congreso, el 22 de julio de 1875 (ley 714), disponia que los amnistiados debían jurar respeto a la Constitución, a las leyes del congreso y a las autoridades de la república. No era el caso de la llamada ley 22.924 de "pacificación", anulada - y no simplemente derogada - por el gobierno constitucional, el 27 de diciembre de 1983. Con dicha anulación efectuada por el gobierno constitucional instalado pocos días antes, por primera vez en la historia argentina se producía una ruptura parcial con la normativa heredada de un "gobierno de facto", mediante la declaración de la nulidad absoluta de uno de sus actos y el consiguiente procesamiento de los interrogantes de las tres primeras juntas militares ${ }^{17}$.
En su mensaje al Congreso el 13 de diciembre, el poder ejecutivo recién instalado justificó su iniciativa con argumentos que servirian más tarde para cuestionar severamente las distintas medidas que llevaron gradualmente a la actual situación de total impunidad, en que a ese respecto se encuentra el país. Estos argumentos eran de tres órdenes: éticos, políticos y juridicos ${ }^{18}$. El proceso hacia la impunidad transcurre en la Argentina post-dictatorial a través de los siguientes actos:

- Las instrucciones del Ministro de Defensa al Fiscal General del Consejo Supremo de las Fuerzas Armadas, el 24 de abril de 1986, para "acelerar" los juicios por las violaciones de los derechos humanos, que incluían en realidad la decisión de restringir el círculo de los justiciables, a través de la aplicación de normas

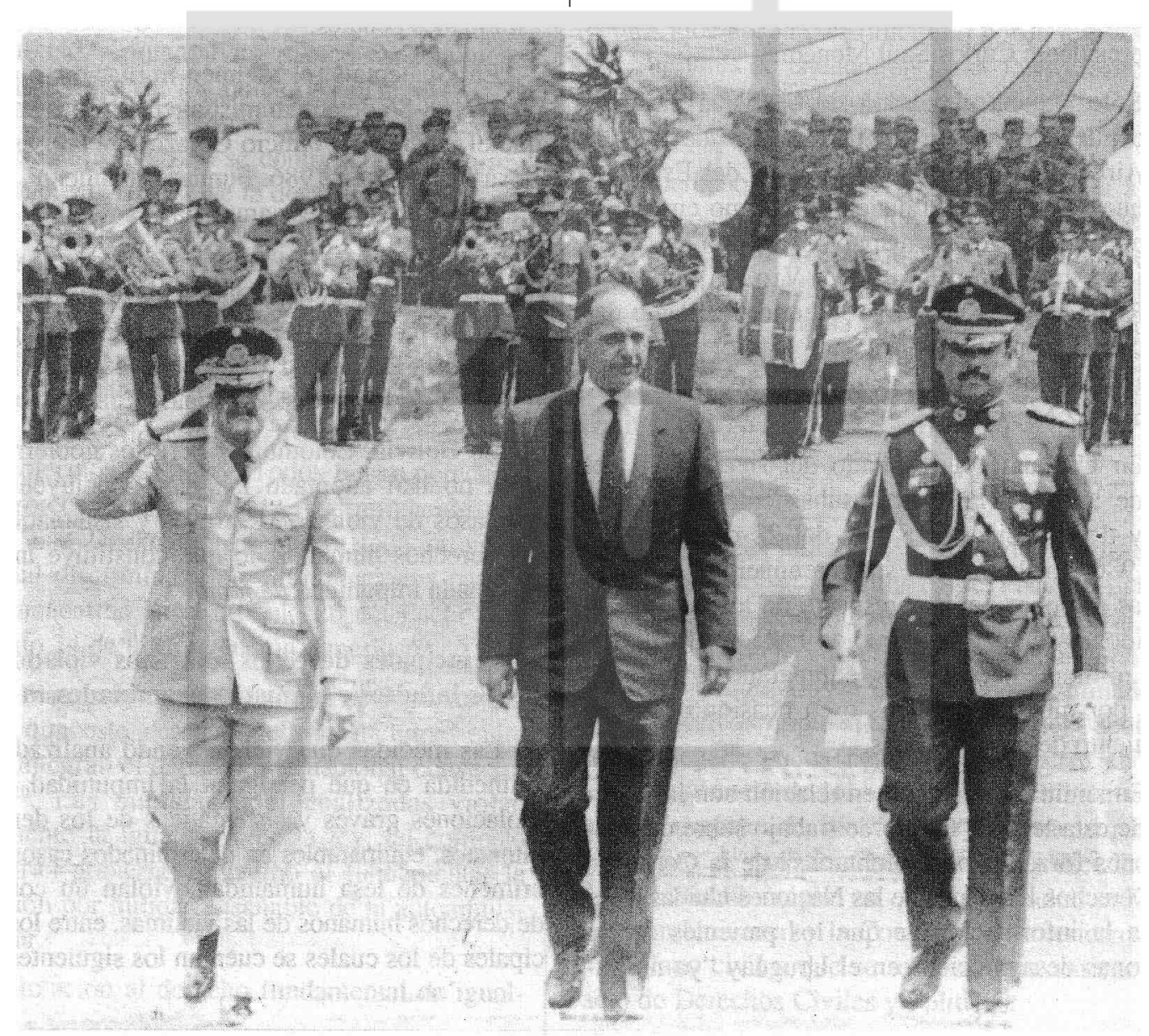


exculpatorias y el perdón de sobreseimientos.

— La ley llamada de "punto final" - ley 23.492, promulgada el 24 de diciembre de 1986 , que establecía la extinción de la acción penal contra todo miembro de las fuerzas armadas, de seguridad, policiales y penitenciarias, que no fuera citado a prestar declaración indagatoria por un tribunal competente dentro de los sesenta días o que no se encontrare procesado ni lo fuere dentro de dicho plazo.

— La promulgación, el 8 de junio de 1987 —siempre durante la administración de Alfonsín-, de la ley 23.521 de "obediencia debida", que estableció una amplia amnistía encubierta.

- Esta ley, no obstante, dejó subsistente el procesamiento de un grupo de altos responsables militares, que fueron indultados por el decreto 1002 del 6 de octubre de 1989 por el actual presidente Carlos Saúl Menem.

- Sólo restaba el perdón de los jefes militares condenados por la Cámara Federal de Buenos Aires —entre ellos dos ex jefes del Estadoque llegó el 29 de diciembre último cuando el presidente Menem dispuso el indulto de los ex jefes militares Videla, Viola, Massera, Ricchieri y Camps y la liberlad, mediante decretos aparte, del dirigente montonero Mario Firmenich y el ex general Carlos Guillermo Suárez Mason.

En Uruguay, el resultado del referéndum del 16 de abril de 1989 deja subsistente la llamada "Ley de caducidad" 15.848, del 22 de diciembre de 1986, por la que el Estado renunció al ejercicio de las acciones penales respecto de los delitos cometidos hasta el 1 de marzo de 1985 por funcionarios militares y policiales, equiparados y asimilados, por móviles políticos o en ocasión del cumplimiento de sus funciones.

En su último informe, en relación con los efectos de esta ley, el "Grupo de trabajo sobre desapariciones forzadas o involuntarias" de la Comisión de Derechos Humanos de las Naciones Unidas, consigna la información de que los parientes de las personas desaparecidas en el Uruguay “ya no pu- dieron proseguir su búsqueda entablando demandas ante tribunales penales". El Grupo agrega: "se afirmó que, de hecho, no había ningún otro medio de acción legal que permitiera determinar el paradero ni la suerte de las personas desaparecidas".

En Chile, la Corte Suprema estableció, el 28 de septiembre de 1990, que el Decreto ley $\mathbf{N}^{\mathbf{2}}$ 2191 , de abril de 1978 , sobre amnistía, era constitucional. El efecto de esta decisión es sobreseer 0 , en su caso, impedir cualquier procedimiento penal contra las personas que, como autores, cómplices o encubridores hubieran tomado parte en actos delictivos tales como la desaparición forzada de personas durante el estado de sitio, es decir, entre el 11 de septiembre de 1973 y el 10 de marzo de 1978 (artículo 1 del decreto ley). Esto obstaculiza el conocimiento de los hechos, independientemente de la determinación de las consiguientes responsabilidades penales.

En Guatemala, el régimen militar dictó el Decreto № 8-86 de autoamnistía, cuatro días antes de que el presidente Vinicio Cerezo Arévalo asumiera su mindato en 1986. Fundamentalmente, el gobiernú civil aceptó esa amnistía.

En El Salvador, en 1987 y durante la presidencia de José Napoleón Duarte, se promulgó una amnistía recíproca, fundamentalmente dirigida a asegurar la inmunidad de prucesamiento de los integrantes de la Fuerza Armada.

En Bolivia, Colombia y Perú los gobiemos civiles no han adoptado medidas concluyentes en los casos de violaciones graves y sistemáticas de los derechos humanos, lo que constituye una denominada impunidad de facto.

\section{Principales derechos humanos violados por los indultos y amnistías examinados}

Las medidas que vienen siendo analizadas, en la medida en que persiguen la impunidad de las violaciones graves y sistemáticas de los derechos humanos, equiparables en determinados casos a los crimenes de lesa humanidad, violan un conjunto de derechos humanos de las víctimas, entre los principales de los cuales se cuentan los siguientes: 
a) Derecho al reconocimiento de la personalidad jurídica

Todo ser humano tiene derecho, en todas partes, al reconocimiento de su personalidad jurídica. Este derecho está reconocido en forma aproximadamente similar por la Declaración Universal (artículo 6), el Pacto Internacional de Derechos Civiles y Políticos (art. 16) y la Convención Americana sobre Derechos Humanos (art.3).

Estas normas garantizan "a todo ser humano cl derecho a ejercilar sus derechos, a entrar en relaciones contractuales y a ser representado en sus acciones legales" y, en ese sentido, "cubre(n) los derechos fundamentales relativos a la "capacidad legal" (el estatuto legal) de una persona".

La situación en que se encuentran las víctimas y sus familiares pucde, en algunos casos, asemejarse a una denegación del reconocimiento de su personalidad jurídica. Esto parece especialmente claro en el caso de los niños desaparecidos y, en general, en el de las víctimas de las desapariciones forzadas, hasta tanto no se compruebe de una manera fehaciente el cese de la desaparición.

b) Derecho a la igualdad ante la ley y la no discriminación en su aplicación

La Declaración Universal lo reconoce en estos términos (cn su arlículo 7): "Todos son iguales ante la Ley y ticnen, sin distinción, derecho a igual protección de la ley. Todos tienen derecho a igual protección contra toda discriminación que infrinja esta Declaración y contra toda provocación a tal discriminación". Formulaciones paralclas se encucntran en cl arlículo 26 del Pacto y en el artículo 24 de la Convención Americana.

Los más exigentes escrutinios se inclinan por afirmar que esic derccho debcría incluirsc entre los que integran el derccho intcrnacional consuetudinario $^{20}$. Las medidas aquí analizadas violan abiertamente la igualdad ante la ley, tal como lo afirmaba el gobierno argentino al fundamentar la derogación por nulidad insanable de la autoamnistía militar.

La violación al derecho fundamental de igual- dad ante la ley aparece aquí en un doble aspecto. La ley y el procedimiento penal tienen a la vez la función de sancionar a los partícipes del delito y proteger a las víctimas y a la sociedad. Por eso, la impunidad establece una doble desigualdad. Porque coloca más allá de la ley a determinadas categorías de delincuentes, que de esa manera eluden la sanción penal, y priva al mismo tiempo a las víctimas de la protección que el orden legal debe acordarles sin discriminaciones de ninguna naturaleza.

\section{c) Derecho a un recurso judicial efectivo}

Está reconocido por la Declaración Universal (artículo 8) de la siguiente forma: "Toda persona tiene derecho a un recurso efcctivo, ante los tribunales nacionales competentes, que la ampare contra actos que violen sus dercchos fundamentales reconocidos por la constitución o por la ley". Normas similares se encucntran en el Pacto (arlículo 2,3 , con relación a los derechos o libcrtades reconocidos en dicho instrumento internacional.

El derecho a la protección judicial está a su vez reconocido en el artículo 25 de la Convención Americana, de la manera más amplia posible: con relación a los derechos reconocidos en la constitución, la ley y la misma Convención. Este derecho cs tan fundamental que sc ha sostenido en relación al mismo que "los derechos humanos sin una efecLiva implementación son sombras sin sustancia"21.

\section{d) Derecho a un juicio justo}

Las garantias judiciales consagradas por la Declaración Universal (artículo 10), cl Pacto (arlículo 14, 1) y la Convención Amcricana (artículo 8,1), también aparecen vulncradas por las amnistías abiertas o encubicrlas y los indultos examinados. Dichas medidas impiden que, a través del "debido proceso legal", pucda llegar a cstablccerse en su caso la inocencia de los impulados. También vulneran el derecho de las víclimas a lograr el reconocimiento de sus derechos en sede judicial, ya sea en la forma amplia en que lo formulan la Declaración Universal y la Convención Americana, o en el plano civil a que se refiere expresamente el Pacto de Derechos Civiles y Políticos. 


\section{La obligación de buscar a las personas acusadas de haber cometido o mandado cometer cualquiera de las infracciones graves.}

\section{e) El derecho al conocimiento de la verdad}

En todos los países en los que se padeció una práctica sistemática de desapariciones forzadas de personas permanece, en lo sustancial, sin respuesta el primero de los dolorosos interrogantes que se plantean los familiares y allegados sobre sus seres queridos: "dónde están”.

En el más reciente informe de una comisión investigadora nacional, de carácter oficial, sobre esta materia --el de la comisión presidida por el jurista Raúl Rettig en Chile- se concluye que "aún persiste en la casi totalidad de los casos de personas detenidas desaparecidas... el problema de determinar el paradero de las víctimas". Y añade, "ciertamente dicha información la poseen quienes tuvieron participación en el ocultamiento de los cadáveres, pero en nuestra legislación no existe disposición alguna que los obligue a poner dichos antecedentes en conocimiento de los tribunales de justicia"22.

Puede afirmarse con fundamento que el derecho de las familias a conocer la suerte corrida por sus miembros en la actualidad es parte del derecho internacional consuetudinario. Dicho derecho está reconocido expresamente en el caso de las personas desaparecidas y fallecidas por el derecho internacional humanitario de los conflictos armados ${ }^{23}$.

La reafirmación convencional de este principio del derecho internacional consuetudinario -inseparable de la larga práctica de la Agencia Central de Búsquedas del Comité Internacional de la Cruz Roja (CICR)— es la norma del Protocolo I de 1977, adicional a los convenios de Ginebra de 1949, que establece en su artículo 32 como principio general de la sección III, dedicada a las personas desaparecidas y fallecidas, "el derecho que tienen las familias de conocer la suerte corrida por sus miembros".

A este derecho se ha referido expresamente la Corte Interamericana de Derechos Humanos en la sentencia del caso relativo a la desaparición de Angel Manfredo Velásquez Rodríguez ${ }^{24}$. En su último informe el "Grupo de trabajo sobre desapariciones forzadas" ha vuelto a referirse al derecho de los familiares a saber, en relación con los indultos y amnistías ${ }^{25}$.

10. Principales obligaciones de los estados violadas por los indultos y amnistías examinados

a) Obligación general de investigar y sancionar las violaciones de los derechos humanos según el derecho internacional consuetudinario

Los estados que mediante los indultos y las amnistías abiertas o encubiertas, o mediante políticas de hecho, han establecido la impunidad de las violaciones graves y sistemáticas de los derechos humanos fundamentales, asimilables a los crímenes de lesa humanidad, han quebrantado la obligación que les impone el derecho internacional consuetudinario de investigar dichas violaciones, cualquiera fuera la fecha en que se cometieron. Igualmente y respecto de las personas contra las cuales existieran pruebas de culpabilidad en la comisión de tales violaciones, han incumplido la obligación de buscarlas, detenerlas, enjuiciarlas y en caso de ser declaradas culpables, castigarlas.

Coherentemente con la asimilación de esas graves violaciones a los crímenes de lesa humanidad, los estados que aseguraran su impunidad, estarian vulnerando los "Principios de cooperación internacional en la identificación, detención, extradición y castigo de los culpables de crímenes de guerra o de crimenes de lesa humanidad", aprobados por la Resolución 3074 (XXVIII) de la Asamblea General, del 3 de diciembre de 1973, que en particular dispone: "los estados no adoptarán disposiciones legislativas ni tomarán medidas de otra indole (...)" que puedan menoscabar sus obligaciones a este respecto (Principio 8). 
b) Obligación general de respetar y garantizar los derechos humanos según el derecho internacional convencional

La impunidad de esas graves violaciones de los derechos humanos mediante indultos y amnistías abiertas o encubiertas, viola la obligación general de todos los estados parte de respetar y garantizar a todos los individuos sometidos a su jurisdicción, los derechos humanos, obligación establecida en el Pacto de Derechos Civiles y Políticos (artículo 2,1, y 2 ) y en la Convención Americana (artículo 1, 1).

En efecto, como lo ha establecido claramente la Corte Interamericana de Derechos Humanos, tanto en el caso Velásquez Rodríguez como en, el caso Godínez Cruz, dichas normas (la Corte se refiere a las de la Convención Americana) contienen la obligación contraída por los estados partes en el respectivo instrumento en relación con cada uno de los derechos protegidos, de tal manera que toda pretensión de que se ha lesionado alguno de esos derechos, implica necesariamente la de que se ha violado también dicha obligación general.

Por otra parte, la Corte también ha establecido en lo que se refiere a la impunidad lo siguiente: "el Estado está (...) obligado a investigar toda situación en la que se hayan violado los derechos humanos protegidos por la Convención. Si el aparato del Estado actúa de modo que tal violación quede impune y no se restablezca, en cuanto sea posible, a la víctima en la plenitud de sus derechos, puede afirmarse que ha incumplido el deber de garantizar su libre y pleno ejercicio a las personas sujetas a su jurisdicción (...)" (idem., № 176). Esta obligación de investigar subsiste mientras se mantenga la incertidumbre sobre la suerte final de la persona desaparecida y según el principio de la continuidad del Estado, permanece con independencia de los cambios de gobiemo (idem., Nos 181 y 184$)^{26}$.

\section{c) Obligación específica de castigar la tortura.}

Establecida en el artículo 4 de la Convención contra la Tortura y Otros Tratos o Penas Crueles,

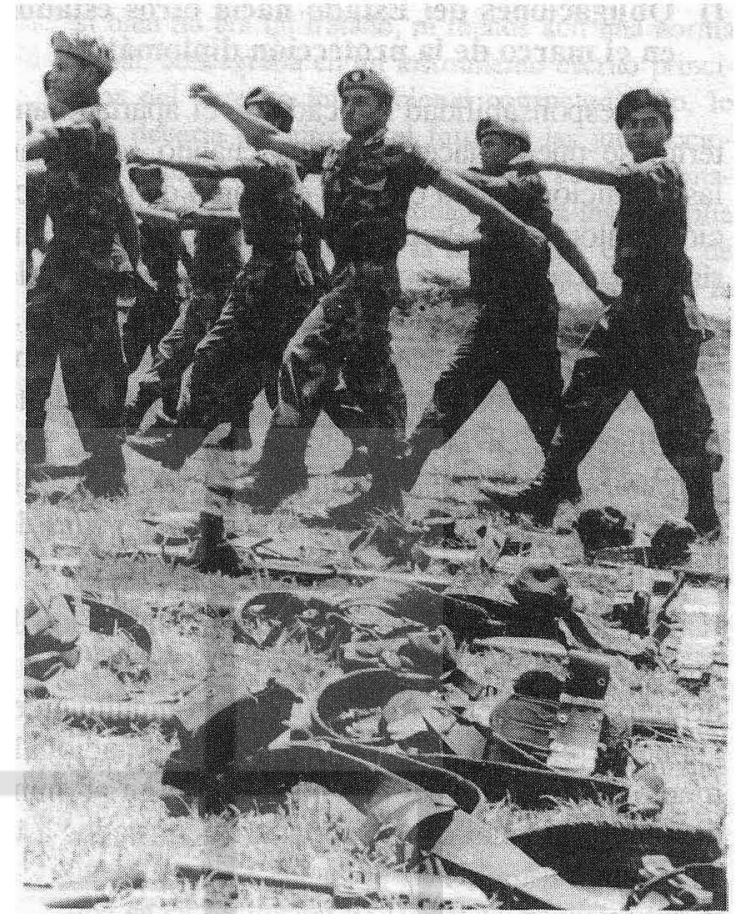

Inhumanos o Degradantes de las Naciones Unidas y en el artículo 6, entre otros, de la Convención Interamericana para Prevenir y Sancionar la Tortura.

d) Obligación específica de procesar a los presuntos responsables de ejecuciones sumarias

Establecida conforme a los párrafos 18 y 19 de los "Principios relativos a una eficaz prevención e investigación de las ejecuciones extralegales, arbitrarias o sumarias", confirmados mediante Resolución 44/162 de la Asamblea General de las Naciones Unidas, el 15 de diciembre de 1989 (ver arriba).

e) Obligación específica de resarcir a las víctimas de las violaciones de los derechos humanos

La impunidad en sus diversas formas dificulta o impide el cumplimiento de esta obligación de los estados establecida por el derecho internacional consuetudinario y por varios tratados internacionales ${ }^{27}$. 
f) Obligaciones del Estado hacia otros estados en el marco de la protección diplomática

La responsabilidad indicada en el apartado anterior se puede hacer efectiva, cuando se reúnan las condiciones para ello, en el marco de la protección diplomática. Precisamente en ese plano, la jurisprudencia internacional ha establecido que "...la responsabilidad del Estado puede configurarse (...) no sólo por una falta de vigilancia en la prevención de los actos dañosos, sino también por falta de diligencia en la persecución penal de los responsables, y en la aplicación de las sanciones civiles requeridas" (Recueil de sentences arbitrales de la ONU, Vol. II, p. 645).

Recuérdese que frente al derecho internacional, una ley nacional (en este caso de amnistía) o un decreto del gobierno (que conceda un indulto en el supuesto examinado) pueden ser internacionalmente ilícitos, al igual que puede serlo un pronunciamiento judicial que los considere ajustados a la Constitución $^{28}$.

\section{g) Obligaciones establecidas por el derecho hu- manitario}

En el caso de que sus normas fueran aplicables, los estados están obligados por el artículo primero común de los cuatro convenios de Ginebra de 1949, a respetar y hacer respetar los convenios en toda circunstancia. Más arriba se indicaron las obligaciones que en materia penal han contraído los estados partes en los convenios, según el comentario publicado por el CICR, obligaciones que en la interpretación amplia que aquí se sustenta, existen incluso en el marco de los conflictos armados internos.

Los estados han acordado un sistema de responsabilidad colectiva en el control y la aplicación de los convenios, estén o no implicados directamente en el conflicto armado de que se trate, conforme a la interpretación del artículo primero común a los cuatro convenios de Ginebra de $1949^{29}$.

En el caso de que un Estado no cumpliera con sus obligaciones en materia penal (incriminación legislativa y búsqueda y procesamiento o extradición de los responsables de las infracciones graves), el sistema de responsabilidad colectiva adop- tado permite afirmar que "una medida concreta que todo Estado parte en los convenios de Ginebra, incluso no comprometido en un conflicto armado, puede tomar, es buscar y presentar ante sus propios tribunales a toda persona sospechosa de haber cometido o de haber ordenado que se cometiera cualquiera de las infracciones graves"30.

En un momento en que está en juego la credibilidad del sistema de protección intemacional de los derechos humanos, quizás estas reflexiones puedan contribuir en algo a esa "coalición contra la impunidad" que afortunadamente ya existe, formada por varias organizaciones nacionales e internacionales de defensa de los derechos humanos.

\section{Notas}

1. El discurso político oficial en el cono sur está bien sintetizado por un periodista - Oscar Raúl Cardoso-, quien en un matutino - Clarín de Buenos Aires del 7 de abril de 1991 — dice refiriéndose a la reciente discusión suscitada en Chile por la publicación del Informe Rettig: "Los portavoces oficiales recurren a Max Weber y derivan de sus escritos una distinción entre la ética de las responsabilidades y la ética de los principios para explicar que hacen lo posible, si no lo deseable".

Este trabajo está elaborado desde el punto de vista del derecho internacional de los derechos humanos, pero es evidente que la lucha contra la impunidad requiere un enfoque integral: ético, jurídico, político, social y cultural.

2. En ese plano y en la discusión académica actual, la conclusión a la que aquí se llega no coincide en un aspecto importante -el relativo a las obligaciones del Estado según el derecho internacional consuetudinario, con la sostenida en el informe de síntesis del coloquio del Aspen Institute, elaborado por Alice H. Henkin: "la conferencia consideró si la legislación internacional requiere que los estados castiguen a los violadores de los derechos humanos. Se acordó que no existía una obligación general, según la legislación internacional para castigar a estos violadores. Varios tratados internacionales, sin embargo, pueden requerir el castigo expresa o implícitamente". Ver State Crimes, Punishment or Pardon. Papers and Report of the Conference. Queenstown, Maryland, 1989, p. 4.

3. La ley comporta dos elementos, un elemento imperativo y un elemento racional. La ley es una voluntad formulada. La disociación de estos dos elemen- 
tos es excepcional en el derecho interno: es la técnica de las leyes interpretativas, en las que el texto no expresa una nueva voluntad, sino que aclara la voluntad ya expresada por la ley que se interpreta. Esa disociación es corriente, en cambio, en el derecho intemacional, en el que con frecuencia la voluntad tiene una existencia en la costumbre antes de su formulación en un texto. Para esta cuestión teórica, pero de innegable importancia en la lucha contra la impunidad a través del derecho intemacional, ver Claude Lombois, Droit Penal International, $\mathrm{Pa}$ rís, Dalloz, 1979, párrafos 48 y siguientes y pár afo 188 con la nota respectiva.

4. Son concordantes con dicha norma los artículos 6 , 1 y 9, 1 del Pacto de Derechos Civiles y los artículos 4 y 7, 1 y 7, 2 de la Convención Americana de Derechos Humanos, entre otras normas del derecho internacional de los derechos humanos. Sobre el estatuto de jus congens reconocido a este "núcleo esencial" ver Richard B. Lillich, "Civil Rights", en Theodor Meron et al., Human Rights in International Law: Legal and Policy Issues. Oxford, Clarendon Press, 1984, p. 120 y sig. Téngase en cuenta que según el Pacto de Derechos Civiles y Políticos, el derecho a la vida y la protección contra la tortura son intangibles, vale decir su derogación está prohibida (artículo 4, 2 del Pacto).

5. Ver Richard B. Lillich, op. cit., en nota 4, p. 127, notas 69 y 70 .

6. Ver a este respecto N. W. Dinh, P. Daillier y A. Pellet, Droit international public. 2e. édition, París, L. G. D. J,. 1980, pár afo 150. Desde hace tiempo, prestigiosos autores de distintos sistemas jurídicos han elaborado una doctrina en ese sentido. Juristas occidentales como I. Brownlie hacen figurar entre los crímenes intemacionales la violación de toda obligación derivada de una norma de jus cogens. I. Brownlie, "Principles of Public Intemational Law", pp. 415 y siguientes. Citado por P. M. Dupuy quien manifiesta reservas al respecto- en "Observations sur le 'Crime International de l'Etat', Extrait de la Revue Générale de Droit International Public", abril-junio 1980, № 2, París, Pedone, 1980, pp., 10 y sig.

En los años que siguieron a la adopción de la Declaración Universal de Derechos Humanos se señaló que sus principios no carecían de protección penal, si se trataba de las más graves violaciones, como el genocidio.

Una temprana posición favorable a la extensión de la protección penal internacional de los derechos humanos fue la del magistrado belga Joseph Dautricourt, quien estimó que la Declaración Universal, si bien no era un tratado, ni menos aún una norma penal, consagraba en un instrumento escrito principios del derecho internacional consuetudinario, lo que debería permitir en el futuro a las jurisdicciones internacionales la represión de su quebrantamiento. Este autor era partidario de la tesis amplia que llevaría a incluir en la noción del crimen de lesa humanidad todo atentado a los derechos de la persona humana, incluida la libertad de trabajo y de educación, aunque en su momento esta posición no prosperó y se prefirió una definición restrictiva, abarcadora del genocidio, pero no extendida a otras conductas. (Ver Antonio Quintano Ripollés, Tratado de derecho penal internacional e internacional penal, Madrid, Instituto "Francisco de Vitoria", 1955, Tomo I, pp. 345 y ss).

Estos debates sólo tienen un interés histórico, ya que hoy se puede afirmar que el desarrollo progresivo de la protección penal internacional de los derechos humanos fundamentales se fue afirmando con claridad en el plano de los preceptos, aunque con mucho menos energía y eficacia en el de su aplicación.

La Asamblea General de las Naciones Unidas ratificó en su resolución 95 (I) del 11 de diciembre de 1946, los principios del derecho internacional reconocidos por el Estatuto y por las sentencias del tribunal de Nuremberg. La Convención para la Prevención y la Sanción del Delito de Genocidio de 1948 (artículo I) "confirmó" que el genocidio, ya sea cometido en tiempo de paz o en tiempo de gueпа, "еs un delito de derecho intemacional", pero la Convención no es autoejecutoria (artículo V) y nunca llegó a crearse la corte penal internacional mencionada en su Artículo VI. A su vez, la Convención Internacional sobre la Represión y el Castigo del Crimen de Apartheid de 1973, en su artículo I, 1 declara que el apartheid es un "crimen de lesa humanidad" y que las políticas y prácticas análogas de segregación y discriminación racial, definidas en el artículo II de la Convención, "son crímenes que violan los principios del derecho internacional". Asimismo, en su artículo 1, 2, la Convención declaró "criminales las organizaciones, las instituciones y los particulares que cometen el crimen de apartheid". La Convención no es autoejecutoria (artículo IV) y el artículo $V$ establece reglas de competencia más amplias que las de la Convención contra el Genocidio. La resolución 2184 (XXI), del 12 de diciembre de 1966, de la Asamblea General condenó expresamente como crimen de lesa humanidad la violación de los derechos económicos y políticos de la población autóctona. 
7. A partir de entonces se establecen dos categorías de responsabilidades enteramente diferentes: (a) la que resulta de una infracción grave a una norma que establece una obligación internacional de importancia fundamental para la comunidad intemacional en su conjunto; (b) la que resulta de infracciones menos graves. Sobre este tema y para mayores referencias bibliográficas, ver la comunicación del autor de este trabajo en "La desaparición forzada como crimen de lesa humanidad", Coloquio de Buenos Aires, Grupo de Iniciativa, Buenos Aires, 1988, pp. 149 y ss.

8. "Barcelona Traction: Nouevelle requete, Belgique c/Espagne, deuxieme phase, arret du 5 février 1970. CIJ", Rec., 1970, p. 3. y "Réserves a la Convention pour la prévention et la répression du crime de génocide, avis du 28 mai 1951", en Petit manuel de jurispridence de la Cour Internationale de Justice, París, Editions A. Pedone, 1984, p. 235. En el pronunciamiento citado en primer lugar dijo la CIJ: "Debe establecerse en particular una distinción esencial entre las obligaciones de los estados hacia la comunidad internacional en su conjunto y las que nacen frente a otro Estado en el marco de la protección diplomática. Por su naturaleza, las primeras conciernen a todos los estados. Vista la importancia de los derechos en cuestión puede considerarse que todos los estados tienen un interés jurídico en que esos derechos sean protegidos, las obligaciones de que se trata son obligaciones erga omnes. Estas obligaciones derivan por ejemplo, en el derecho internacional contemporáneo, de haberse puesto fuera de la ley los actos de agresión y de genocidio, pero también de los principios y las reglas concernientes a los derechos fundamentales de la persona humana, comprendida la protección contra la práctica de la esclavitud y la discriminación racial. Ciertos derechos de protección correspondientes se han integrado al derecho internacional general (...); otros han sido reconocidos por instrumentos internacionales de carácter universal o cuasi universal".

9. Corte Interamericana de Derechos Humanos, Caso Velásquez Rodríguez, sentencia del 29 de julio de 1988, párrafo 158 y caso Godínez Cruz, sentencia del 20 de enero de 1989, párrafo 161.

10. La Convención contra la Tortura y Otros Tratados - Penas Crueles, Inhumanos o Degradantes de las Naciones Unidas no olorga esa calificación jurídica a los tormentos, pero establece varias de sus consecuencias. Así, su artículo, 2, 3, declara que "no podrá invocarse una orden de un funcionario superior o de una autoridad pública como justificación de la tortura", lo que constituye una enunciación aún más terminante, respecto de la obediencia a las órdenes superiores, que la contenida en el Principio № 4 de Nuremberg. Igualmente, la Convención establece la llamada competencia universal (artículo 5).

11. José Zalaguett afirma: "según la Convención sobre el genocidio, parecería que, en realidad, el castido siempre debe ser aplicado a aquellos encontrados culpables de tales crímenes. La Convención de la tortura, en cambio, parece demandar que esas ofensas deben ser declaradas punibles por la ley, pero no excluye la posibilidad de amnistías subsecuentes o de perdones". En op. cit., en nota 2, p. 42.

12. La Convención considera crímenes de lesa humanidad los cometidos tanto en tiempo de guerra como en tiempo de paz, según la definición dada en el Estatuto del Tribunal Militar Intemacional de Nuremberg y confirmada por la Asamblea General, así como la expulsión por ataque armado u ocupación $\mathrm{y}$ los actos inhumanos debidos al apartheid y el delito de genocidio, aun si estos actos no constituyen una violación del derecho interno del país donde fueron cometidos. La inclusión expresa de las desapariciones forzadas de personas entre los crímenes de lesa humanidad es parte del desarrollo progresivo del derecho internacional. Dos organizaciones regionales intergubernamentales han adoptado resoluciones condenando la práctica de las desapariciones forzadas como crímenes de lesa humanidad: la Organización de Estados Americanos (Resolución AG/RES. 666 (XIII-0/83), del 18 de noviembre de 1983, artículo 4) y la Asamblea Parlamentaria del Consejo de Europa (Resolución 828, del 26 de septiembre de 1984).

13. En lo que se refiere en particular al Protocolo II, aplicable al conflicto armado interno de El Salvador, se ha entendido que las infracciones graves a dicho Protocolo, están constituidas por lo menos por la violación de las obligaciones enunciadas en dicho instrumento intemacional que deben ser observadas "en todo tiempo y en todo lugar", o "en todas las circunstancias". Tal es el caso precisamente de las garantías fundamentales establecidas en el artículo 4, párafos 1 y 2 del artículo 13 sobre protección de la población civil.

14. Ver Documento F/C.4/Sub.2/1985/16, del 21 de junio de 1985, párrafo 62.

15. Ver el informe de la Comisión Nacional de Verdad y Reconciliación de Chile. Al crearla, el presidente Patricio Aylwin Azocar le dio por misión (Decreto supremo 355 , del 25 de abril de 1990, artículo primero) "contribuir al esclarecimicnto global de la verdad sobre las más graves violaciones de los de- 
rechos humanos", entendiendo que éstas comprendían "las situaciones de detenidos desaparecidos, ejecutados y torturados con resultado de muerte, en que aparezca comprometida la responsabilidad moral del Estado por actos de sus agentes o de personas a su servicio, como asimismo los secuestros y los atentados contra la vida de personas cometidos por particulares bajo pretextos políticos".

16. Ver documento citado en nota 14 , párrafo 73 , nota 29, donde se cita "Publications de la Cour Européenne des droits de l'homme, Série a: Arrets et décisions, vol. 25, Affaire Irlande contre RoyaumeUni, arret du 18 janvier 1978", par. 159 y 74 reproducido aquí en el texto.

17. Ver Enrique Groisman, compilador, El derecho en la transición de la dictadura a la democracia: la experiencia en América Latina, Bueno Aires, Centro Editor de América Latina, 1990, Tomo 1, pp. 40 y sig.

18. Eticos en primer lugar, ya que el mantenimiento de la impunidad "constituiría una claudicación muy seria de élementales exigencias de justicia, que no deben confundirse con un deleznable espíritu de venganza, la omisión del castigo de hechos que desconocieron de la manera más brutal y completa la dignidad de la persona humana". Este castigo ejemplificador - añadía el mensaje - es necesario "para dejar firmemente establecido que la sociedad argentina no está dispuesta a tolerar que se usen a los seres humanos como meros objetivos susceptibles de cualquier grado de manipulación y degradación en aras de objetivos supuestamente loables".

Según el poder ejecutivo, un eventual mantenimiento de la autoamnistía militar produciría desde el punto de vista político por lo menos dos efectos nefastos: (a) extendería indiscriminadamente sobre las instituciones armadas en su conjunto una presunción de responsabilidad que sólo debería recaer en diferentes grados sobre parte de sus integrantes; (b) la posibilidad de investigar y castigar los hechos se consideraba esencial para que los órganos constitucionales tuviera en el futuro "el control absoluto del monopolio de la fuerza". Desde el punto de vista jurídico se objetaba la autoamnistía, porque violaba el principio de igualdad ante la ley, consagrado por el artículo 16 de la Constitución argentina, e implicaba la concesión de facultades extraordinarias a los poderes públicos, en contravención al artículo 29 de la Constitución nacional.

19. Para las distintas citas sobre este tema ver Richard B. Lillich, op. cit., p. 131. Cuando se adoptó la declaración universal, el derecho al reconocimiento del individuo como persona frente al derecho se consideró tan importante como los derechos que salvaguardaban su integridad física. El principal autor intelectual de la declaración, René Cassin, señaló que mientras la prohibición de la esclavitud y la servidumbre protegían contra "la degradación del individuo desde el punto de vista físico, el artículo 6 estaba destinado a combatir y denegar la posibilidad de esa degradación desde el punto de vista legal".

20. "Propiamente limitado, sin embargo, el derecho considerado en esta subsección probablemnte ahora se ha convertido en una costumbre legal internacional". Ver Richard B. Lillich, op. cit., p. 133.

21. Ver cita de Humphrey en Richard B. Lillich, op. cit., p. 134. Se ha afirmado que la referencia a la constitución y la ley, efectuada por la Declaración Universal, muestra la amplitud del derecho aquí reconocido, ya que en general el catálogo de derechos declarados por la legislación interna es aun más amplio - al menos teóricamente-que los reconocidos por el derecho internacional. De todas formas, el derecho a la protección judicial aparece claramente violado en todos los casos en los que las víctimas de la tortura, de las desapariciones forzadas y ejecuciones sumarias, se ven privadas de un recurso efectivo ante los tribunales de justicia.

22. Informe de la Comisión de verdad y reconciliación, Cuarta parte, Capítulo III, B, "Penalización por ocultamiento de información". Santiago de Chile, Edición Especial de La Nación, 1991.

23. Ver "'Le refus de l'oubli. La politique de disparition forcée de personnes. Colloque de Paris. Janvier/février 1981'. Rapport génćral par Louis Joinet". París, Berger Lvrault, 1982, p. 302. Como se concluyó en esa oportunidad, los derechos reconocidos a los familiares y allegados a las víctimas en tiempo de paz deben ser superiores, o por lo menos iguales, a los que se les rcconoce en tiempo de guerra, de acuerdo a los convenios de Ginebra.

24. "El deber de investigar hechos de este género subsiste mientras se mantenga la incertidumbre sobre la suerte final de la persona desaparecida. Incluso si en el supuesto de que circunstancias legítimas de orden jurídico interno no permitieron aplicar las sanciones correspondientes a quienes sean individualmente responsables de delitos de esta naturalcza, el derecho de los familiares de la víctima de reconocer cuál fue el destino de ésta y, en su caso, dónde se encuentran sus restos, representa una justa expectativa que el Estado debe satisfacer con los medios a su alcance" (párrafo 181 de la Sentencia de la Corte Interamericana, del 29 de julio de 1988). En idéntico sentido se expidió la Corte en su 
sentencia del 20 de enero de 1989, en el caso de la desaparición de Saúl Godínez Cruz (párrafo 191).

25. "En algunas instancias se concede un perdón o una amnistía a las personas sospechosas o responsables de violaciones de los derechos humanos, desapariciones inclusive. Estas medidas se justifican por razones políticas y de seguridad nacional, de reconciliación nacional o de pacificación. Pero al Grupo de Trabajo le cuesta aceplar que una consecuencia, de facto o de jure, dc algunas de estas medidas sea impedir que se investigue la sucrte o el paradero de las personas desaparecidas ...".

26. A este respeto, la Corte Interamericana tambićn ha dicho que "Como consecuencia de esta obligación, los estados deben prevenir, investigar y sancionar toda violación de los derechos reconocidos por la Convención y procurar, además, el restablecimiento, si es posible, del derecho conculcado $y$, cn su caso, la reparación de los daños producidos por la violación de los derechos humanos" (Sentencia en el caso Velásquez Rodríguez, párrafo 166). En el mismo sentido, la Corte ha considerado que "cl Estado está en el deber jurídico de prevenir, razonablemente, las violaciones de los derechos humanos, de investigar seriamente con los medios a su alcance las violaciones que se hayan cometido dentro del ámbito de su jurisdicción a fin de identificar a los responsables, de imponerles las sanciones pertinentes y de asegurar a la víctima una adecuada reparación" (sentencia in re Velásquez. Rodrígue\%, páriafo 174).
27. Art. 9, 5 del Pacto Internacional de Derechos Civiles y Políticos, art. 14 de la Convención contra la Tortura y Otros Trats: y Penas Crueles, Inhumanos o Degradantes, art. 03,1 de la Convención Americana sobre Derechos Humanos; Principios Fundamentales de Justicia para las Víctimas de los Delitos y del Abuso de Poder (punto 11), adoptados por la Asamblea General de las Naciones Unidas, en su resolución 40/34, del 29 de noviembre de 1985. Ver asimismo Theo van Boven, "Estudio relativo al derecho de restitución, indemnización y rehabilitación de las víctimas de violaciones flagrantes de los derechos humanos y las libertades fundamentales". Subcomisión de Prevención de Discriminaciones y Protección a las Minorías de las Naciones Unidas, Documento E/CN.4/Sub.2/1990/10, del 26 de julio de 1990.

28. A este respecto, la Corte de La Haya no establece ninguna distinción entre los actos internos, a los que se considera simples "hechos" frente al derecho intemacional. Fallo del 25 de mayo de 1926 de la Corte Permanente de Justicia Intemacional en el asunto de los "intereses alemanes en la Alta Silesía polaca".

29. CICR. "Conferencia de expertos gubernamentales, Ginebra, 24 de mayo - 12 de junio de 1971. Informe sobre los trabajos de la conferencia", p. 15 y 124.

30. Michcl Vcuthcy, Guérilla et droit humanitaire, Ginebra, CICR, 1983, p. 321. 